\title{
Determinants of diabetes comorbidities in Indonesia: a cohort study of non-communicable disease risk factor
}

\author{
Dewi Kristanti*, Ekowati Rahajeng*, Eva Sulistiowati*, Nunik Kusumawardani*, \\ and Frans Dany*
}

\section{ABSTRACT}

\section{BACKGROUND}

Type 2 diabetes mellitus (DM) is a non-communicable disease that constitutes a huge health burden, with the presence of comorbidities of DM adding to it. This study aimed to obtain the main determinants of the combined incidence of DM and its main comorbidities in adults.

\section{METHODS}

This was a further analysis of the Non-Communicable Disease Risk Factor Cohort Study 2011 - 2018 involving 3730 subjects. Data of diabetes-free respondents at baseline were followed up every 2 years for 6 years. Data collection was carried out through interviews and health examinations. All subjects were assayed for blood glucose and lipid parameters. Chi-square test and Cox regression were implemented for data analysis.

\section{RESULTS}

During 6 years of follow-up, DM incidence occurred in 567 (15.2\%) subjects. The most common comorbidities were increased low density lipoprotein (LDL), central obesity, increased total cholesterol, obesity and hypertension. Most of the comorbidities occurred before the diagnosis of DM incidence. The determinants of the combined DM incidence-increased LDL are obesity, hypertension, and a family history of DM. The determinants of the combined DM incidence-central obesity are increased triglycerides, hypertension, male gender, and family history of DM. While the determinants of the combined DM incidence-hypertension are obesity and increased triglycerides.

\section{CONCLUSION}

This study demonstrated a high burden of diabetes incidence with comorbidities among adults. Knowledge of the magnitude of the diabetes comorbidity determinants emphasizes the role of non pharmacological intervention such as weight reduction and dietary modification.

Keywords: Diabetes mellitus incidence, comorbidity, NCDRF Cohort Study, Indonesia
*National Institute of Health Research and Development, Republic of Indonesia

\section{Correspondence:}

Dewi Kristanti

National Institute of Health Research and Development,

Republic of Indonesia

Jalan Percetakan Negara no 29

Jakarta Pusat

Phone (021)4241921

Email: dewikris@litbang.kemkes.go.id, find.dewi@gmail.com.

ORCID ID: 0000-0002-9694-2064.

Date of first submission, September 1, 2020

Date of final revised submission,

December 24, 2020

Date of acceptance, January 52021

This open access article is distributed under a Creative Commons AttributionNon Commercial-Share Alike 4.0 International License

Cite this article as: Kristanti D, Rahajeng E, Sulistiowati E, Kusumawardani N, Dany F. Determinants of comorbidities of diabetes in Indonesia: a cohort study of non-communicable disease risk factor. Univ Med 2021;40:3-13. doi: 10.18051/ UnivMed.2021.v40.3-13 


\section{INTRODUCTION}

Diabetes mellitus (DM) constitutes a global and national health problem. Throughout the world, DM occurs in 463 million individuals aged between 20 and 79 years. Around 79.4 percent of them live in low- and middle-income countries. ${ }^{(1)}$ Indonesia occupies seventh rank among the countries, with the highest number of DM patients of 10.7 million. ${ }^{(1)}$ According to the results of the Indonesian Basic Health Research (Riset Kesehatan Dasar, Riskesdas) the prevalence of DM based on blood sugar examination of persons aged $\geq 15$ years was 6.9 $\%$ in 2013 , increasing to $8.5 \%$ in $2018 .^{(2,3)}$ The highest prevalence of DM was in persons aged 55 years and over, were of female gender, had low education, and resided in rural areas. ${ }^{(3)}$

Comorbidities of DM are one or more chronic conditions occurring in patients with DM or are other diagnosed diseases found concomitantly with DM. ${ }^{(4)}$ All cases of chronic disease are considered to be comorbidities, even though occurring before or after the diagnosis of DM incidence. ${ }^{(5)}$ Comorbidities may be found at the time of diagnosis or at the time of followup. ${ }^{(6)}$ According to the results of several studies worldwide, hypertension is the main comorbidity in DM, with a proportion of around 34.9 $71.0 \%$. $^{(7-9)}$

According to the Indonesian Society of Endocrinology (Perkumpulan Endokrinologi Indonesia), in Indonesia the main comorbidities of DM can be in the form of hypertension, dyslipidemia, obesity and coagulation disorders. ${ }^{(10)}$ Based on a cross-sectional study involving patients with DM who were participants of the Chronic Diseases Management Program (Program Pengelolaan Penyakit Kronik, PROLANIS) in a community health center (Puskesmas) in Jakarta, it was found that the proportion of patients with DM and the comorbidity of obesity attained $63.9 \% .^{(11)}$

Based on the results of a retrospective observational study, concordant as well as discordant comorbidities in patients with DM were proven to increase healthcare utilization and costs. ${ }^{(12)}$ Comorbidities, particularly depression, also cause a decrease in the quality of life. ${ }^{(13)}$ In addition, comorbidities increase the risk of complications, such as renal failure, and interfere with diabetic control. ${ }^{(14)}$

The presence of comorbidities in diabetes mellitus and its risk factors have been reported in various studies. ${ }^{(15-17)}$ However, in contrast with a previous study on the influence of the principal comorbidities such as hypertension, obesity and dyslipidemia, our study investigated their association with the time of occurrence of DM incidence in adults. The present study aimed to find the determinants of DM incidence and its main comorbidities in adult subjects.

\section{METHODS}

\section{Research design}

This study was a further analysis of the Cohort Study on NCD Risk Factors (Studi Kohor Faktor Risiko PTM), hereafter designated NCDRF cohort study, that was conducted by the National Institute of Health Research and Development for the years 2011-2018 in Bogor city, West Java. Baseline data were collected in three stages, namely in the years 2011, 2012 and 2015, whereas periodic follow-up was performed every four months for a limited number of parameters (data on blood pressure and anthropometrics) and every two years for the complete set of parameters. ${ }^{(18)}$

\section{Study subjects}

The study population comprised the subjects of stages 1 and 2 of the NCDRF cohort study (2011 and 2012 baseline data), whereas the study sample consisted of subjects who were free of $\mathrm{DM}$ on initial observation. The inclusion criteria were subjects who participated fully in the baseline data collection (interviews and health examinations) and in the biennial follow-ups. Each of the groups of subjects had been followed-up for 6 years, where the subjects of stage 1 were followed up in the years 2013, 2015 and 2017, 
while the subjects of stage 2 were followed up in the years 2014, 2016 and 2018. The exclusion criteria were subjects with incomplete data for the study variables of interest.

\section{Measurements}

DM incidence were defined as subjects who had ever been diagnosed with DM by health personnel, or who had a fasting blood glucose concentration of $\geq 126 \mathrm{mg} / \mathrm{dL}$ or a blood glucose concentration of $\geq 200 \mathrm{mg} / \mathrm{dL}$ two hours after loading with $75 \mathrm{~g}$ glucose in $250 \mathrm{~mL}$ drinking water. The definition of blood glucose concentration was according to the 2019 criteria of the Indonesian Society of Endocrinology (Perkumpulan Endokrinologi Indonesia, PERKENI). ${ }^{(10)}$

The comorbidities evaluated in this study were obesity, central obesity, hypertension, dyslipidemia, coronary heart disease, and stroke. The comorbidities could occur before, at the time of, or after the diagnosis of DM incidence and were determined from interviews, measurements, and ancillary examinations.

Obesity was defined as a body mass index (BMI) of $\geq 25 \mathrm{~kg} / \mathrm{m}^{2}$ based on the criteria of obesity in Asian populations according to the PERKENI 2019 guidelines for dyslipidemia management, ${ }^{(19)}$ whereas central obesity was defined as an abdominal circumference of $>90$ $\mathrm{cm}$ for males or $>80 \mathrm{~cm}$ for females based on the PERKENI 2019 criteria. ${ }^{(10)}$ Hypertension was defined according to the JNC VIII criteria as a systolic blood pressure of $\geq 140 \mathrm{mmHg}$ or diastolic blood pressure of $\geq 90 \mathrm{mmHg}$ at rest. ${ }^{(20)}$ Dyslipidemia was defined as abnormal lipid metabolism, marked by an increase or a reduction in the plasma lipid fraction. The main lipid fraction abnormalities were increased total cholesterol $(\geq 200 \mathrm{mg} / \mathrm{dL})$, LDL $(\geq 100 \mathrm{mg} / \mathrm{dL})$, increased triglycerides $(\geq 150 \mathrm{mg} / \mathrm{dL})$, or decreased HDL $(<40 \mathrm{mg} / \mathrm{dL}$ for males and $<50 \mathrm{mg} / \mathrm{dL}$ for females). ${ }^{(10,19)}$ Coronary heart disease (CHD) was defined as ischemic heart disease or infarction on the resting or active/stressed electrocardiogram (EKG). ${ }^{(18)}$ Stroke was defined as a history of stroke based on interviews and the finding of sequelae in the form of neurological deficits. ${ }^{(18)}$

The independent variables consisted of the sociodemographic characteristics (age, gender, marital status, highest level of education, and family history of DM). Age was in the form of continuous data, gender consisted of male and female, highest level of education consisted of low education (unschooled to finished elementary school), middle (finished junior and/or senior high school), and high (university graduate), marital status consisted of married, single, and divorced, and family history of DM was based on presence of family members who had been diagnosed with DM or had died as a result of DM. ${ }^{(18)}$

The behavioral risk factors investigated were smoking status, physical activity, and mentalemotional abnormality. Smoking status was defined as the smoking behavior in the last month, and was categorized into non-smoker, ex-smoker, and active smoker. Physical activity was defined as the intensity of daily activities of living and was calculated from the weight of the type of physical activity and its duration. Physical activity was categorized as adequate ( $\geq 600$ MET per week) and poor ( $<600$ MET per week). ${ }^{(21)}$ Mental-emotional abnormality was defined as the psychological condition of an individual that has an influence on mood, thoughts, and behavior and was measured by answering 20 items in a selfreported questionnaire (SRQ) that described the condition in the last two weeks. ${ }^{(22)}$

\section{Data collection procedures}

Data collection in the NCDRF cohort study was conducted according to the WHO STEPS Approach for surveillance of NCD risk factors. ${ }^{(23)}$ The STEPS instrument covers three different levels of "steps" of risk factor assessment, consisting of questionnaires on demographic information and behavioral measurements, physical measurements, and biochemical measurements. Collection of data on socio-demographics, behavior, and medical history was performed by trained enumerators in STEP 
1, using a questionnaire that was specially developed for the Indonesian NCDRF cohort study. In STEP 2 the blood pressure was measured 2-3 times with an interval of 5 minutes between measurements, using an AND digital blood pressure monitor on the left upper arm with the subject in the sitting position. Anthropometric measures were determined by measuring height with a fiberglass stadiometer, weight with AND digital scales, and abdominal circumference using measuring tape. The determination of blood pressure and anthropometric measures was performed by trained health personnel from the Bogor Municipal Health Service. The neurological examinations to determine stroke sequelae was done by a team of neurologists. The EKG was recorded using electrocardiograph was provided with the Minnesota code, and the EKG results were read by a cardiologist and validated by two cardiology consultants. The laboratory examinations comprised fasting and 2-hour postprandial blood glucose, total cholesterol, triglycerides, low density lipoprotein (LDL), and high density lipoprotein (HDL) using enzymatic clinical chemistry methods and were performed in STEP 3 by a certified medical laboratory.

\section{Statistical analysis}

Descriptive analysis was used to for the subject characteristics at baseline and follow-up in the second, fourth and sixth years. Bivariate analysis using the chi-square test was done to determine the distribution of DM incidence based on the presence of comorbidities and the time of comorbidity onset. Multivariate analysis using the Cox regression test was done to evaluate the determinants that play a role in the combined incidence of DM with the main comorbidities. Variables with $p$ values of $<0.25$ in the bivariate analysis were selected for further multivariate analysis. In the multivariate analysis, the variables that were statistically non-significant and were not confounders, were removed one by one from the model, so that the final model contained the adjusted hazard ratios of the independent variables that were determinants. A 95\% confidence interval and a 5\% level of significance was used to interpret statistical significance.

\section{Research ethics}

The NCDRF cohort study was submitted annually for review by and ethical approval from the Commission of Health Research Ethics of the National Institute of Health Research and Development. All requirements for the subjects' informed consent had been met and had been approved prior to data collection. The numbers of the ethical approvals were as follows: No.KE.01.08/EC/485/2011; No.KE.01.05/EC/ 394/2012; No.LB.02.01/5.2/KE.215/2013; No.LB-02.01/5.2/KE.143/2014; No.LB.02.01/ 5.2/KE.135/2015; No.LB.02.01/5.2/KE.042/ 2016; No.LB.02.01/2/KE.108/2017; and No. LB.02.01/2/KE.076/2018.

\section{RESULTS}

\section{Flow of subject selection}

The baseline samples in stages 1 and 2 comprised 5296 subjects. Of this number, 467 subjects had DM at baseline and were removed from the samples, so there were 4829 subjects without DM. There were 1099 subjects that did not meet the criteria, so that the final sample for analysis was 3730 subjects. The flow of subject selection is depicted in Figure 1.

\section{Subject characteristics}

The subject characteristics are presented in Table 1. Initially there were 3730 subjects, then the attendance rates (response rates) decreased to $91.59 \%, 86.06 \%$ and $82.5 \%$, respectively, during the follow-ups in the second, fourth and sixth years. The cumulative incidence of DM was 567 subjects (15.2\%) in the six years of follow-up. According to socio-demographic characteristics, the mean age of the subjects at baseline was $43.7 \pm 10$ years, the majority were females, married, and had a medium educational level. The most frequent types of comorbidities found at baseline as well as at biennial followups were obesity, central obesity and increased 


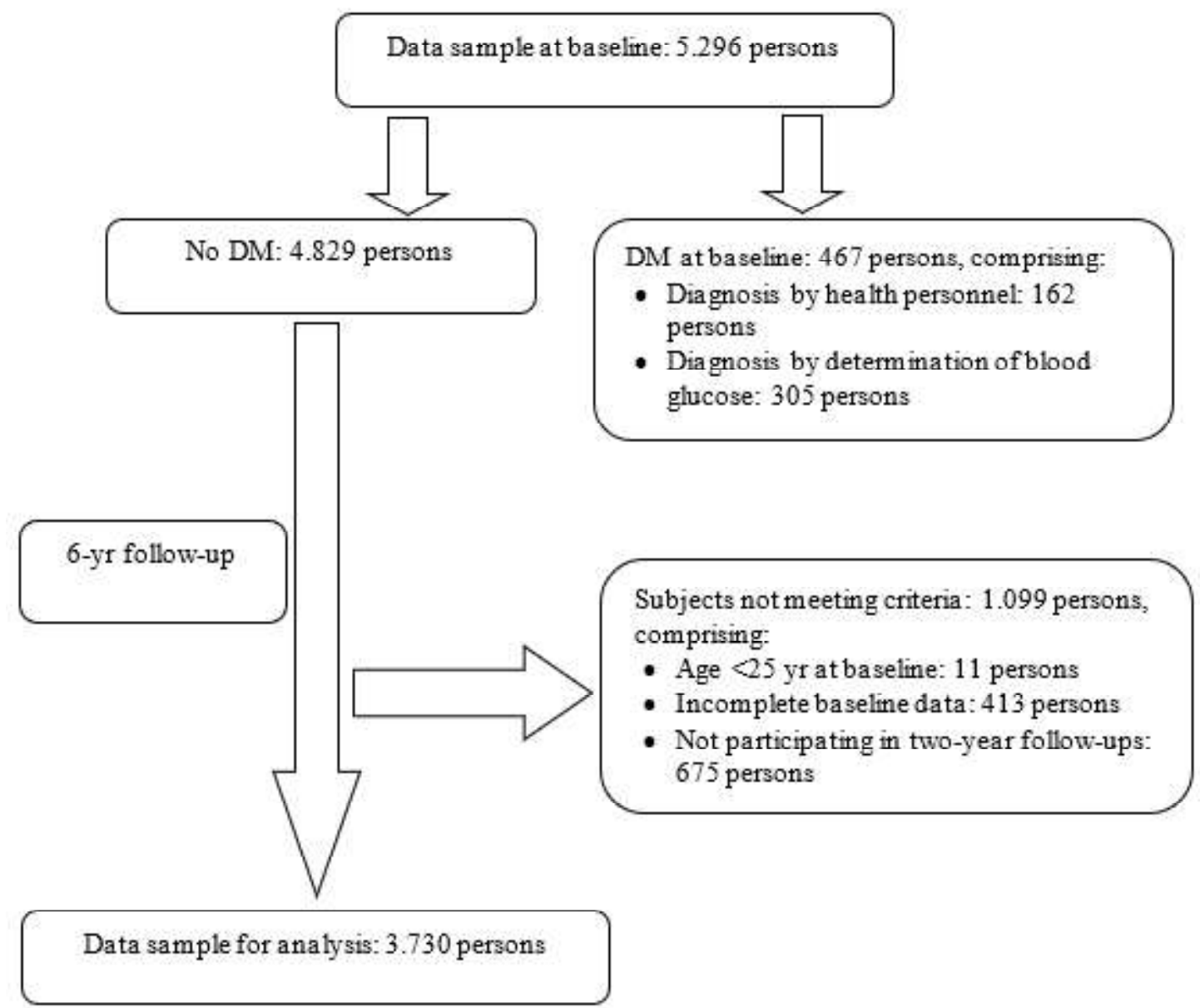

Figure 1. Flow of sample selection in cohort study

LDL. Based on the number of comorbidities, from the start of the data collection only less than 5 percent of subjects were free from comorbidities, more than half of the subjects had 1-3 comorbidities and almost $40 \%$ of subjects had 4-6 comorbidities. During follow-up the proportion of subjects with 4-6 comorbidities increased to $51.4 \%$ in the sixth year of followup.

For the subjects with DM incidence, bivariate analysis was performed to determine the proportion of comorbidities occurring at each follow-up, as presented in Table 2. It was found that LDL increased in nearly all subjects. Obesity, central obesity and increased total cholesterol occurred in around $80 \%$ of subjects. Hypertension, low LDL and increased triglycerides occurred in $57-78 \%$ of subjects, while comorbidities in the form of CHD and stroke occurred in a minority of subjects.
Based on the time of appearance of the comorbidities, in Table 2 are presented the proportions of occurrences of each of the comorbidities that are categorized as before, during, or after diagnosis of DM incidence. Particularly for the follow-up results in the sixth year, the proportions of occurrence of comorbidities after diagnosis of DM incidence could not be filled in because the available data were only up to the sixth year of follow-up. It was found that for obesity, central obesity, and hypertension, the largest proportion occurred before the diagnosis of DM incidence. The largest proportion of the increased total cholesterol, increased LDL and low HDL concentration occurred before diagnosis of DM incidence. Meanwhile, the largest proportion of increased triglyceride concentrations occurred at the time of diagnosis of DM incidence. The comorbidity CHD occurred most frequently at the time of 
Table 1. Distribution of subject characteristics by follow-up period

\begin{tabular}{lcccc}
\hline Subject characteristic & \multicolumn{4}{c}{ Follow-up } \\
\cline { 2 - 5 } & $\begin{array}{c}\text { Baseline } \\
\mathbf{n}=\mathbf{3 7 3 0}\end{array}$ & $\begin{array}{c}\text { Year } \mathbf{2} \\
\mathbf{n = 3 4 1 6}\end{array}$ & $\begin{array}{c}\text { Year } \mathbf{n} \\
\mathbf{n}=\mathbf{3 2 1 0}\end{array}$ & $\begin{array}{c}\text { Year 6 } \\
\mathbf{n}=\mathbf{3 0 7 7}\end{array}$ \\
\hline Incidence of DM (n) & - & 157 & 129 & 281 \\
Age (yr) & $43.7 \pm 10.0$ & $45.7 \pm 9.9$ & $47.6 \pm 9.8$ & $49.6 \pm 9.9$ \\
Gender & & & & \\
$\quad$ Female & 68.5 & 70 & 70.7 & 71.1 \\
$\quad$ Male & 31.5 & 30 & 29.3 & 28.9 \\
Marital status & & & & \\
$\quad$ Married & 85.1 & 85.1 & 83.9 & 80.8 \\
Single & 5.8 & 5.3 & 4.2 & 3.5 \\
$\quad$ Divorced & 9.1 & 9.6 & 11.9 & 15.7 \\
Educational level & & & & \\
High & 6.4 & 6.3 & 6.5 & 5.8 \\
Middle & 57.6 & 57.8 & 57.9 & 58.8 \\
$\quad$ Low & 36 & 35.9 & 35.6 & 35.4 \\
Comorbidities & & & & \\
$\quad$ Obesity & 45.5 & 50.7 & 51.8 & 55.3 \\
Central obesity & 41.1 & 49.3 & 58.1 & 62.2 \\
Hypertension & 29.4 & 29.7 & 28.5 & 37.5 \\
Increased total cholesterol & 27.4 & 45.1 & 50.2 & 61.2 \\
Increased triglycerides & 16.5 & 18.8 & 19.9 & 25.5 \\
Increased LDL & 82.3 & 81.9 & 81.7 & 82.9 \\
Low HDL & 39.4 & 38.7 & 38.8 & 35.1 \\
CHD & 16 & 18.6 & 18.9 & 20.1 \\
Stroke & 1.8 & 2.8 & 3.3 & 3.8 \\
Number of comorbidities & & & & \\
None & 3.9 & 4.3 & 4.6 & 3.3 \\
1-3 & 53.1 & 51.3 & 48.8 & 41.6 \\
4-6 & 39.9 & 41.9 & 4.7 & 51.4 \\
7-9 & 2.7 & 2.5 & 1.8 & 3.7 \\
\hline
\end{tabular}

Data presented as n (\%), except for age (mean \pm SD)

diagnosis of DM incidence,, whereas stroke had different patterns at each follow-up.

The principal comorbidities that were evaluated in multivariate analysis were the three types of comorbidities having the highest proportion in bivariate analysis, namely increased LDL, central obesity, and hypertension. The independent variables that were entered into the initial model were age, gender, educational level, marital status, family history of DM, smoking status, physical activity, mental-emotional abnormalities, obesity, increased triglycerides, and hypertension. All independent variables were taken from the baseline data. Variables that were identical to the types of comorbidities under current analysis were not included. Central obesity was not entered simultaneously into the initial model because it had a lower crude hazard ratio (HR) than obesity, while from among the parameters of dyslipidemia only the triglyceride concentration was taken because it had the largest crude HR as compared with the other parameters.

The results of the multivariate analysis can be seen in Table 3. The determinants in the combined DM incidence and increased LDL were obesity, hypertension, and family history of DM. The determinants in the combined DM incidence and central obesity were increased triglycerides, hypertension, male gender and family history of $\mathrm{DM}$, whereas the determinants in the combined DM incidence and hypertension were obesity and increased triglycerides. 
Table 2. Type and time of appearance of comorbidities related to incident DM

\begin{tabular}{|c|c|c|c|c|c|c|c|}
\hline \multirow[t]{2}{*}{ Comorbidities } & \multirow[t]{2}{*}{$\begin{array}{c}\text { Time of appearance } \\
\text { of comorbidities }\end{array}$} & \multicolumn{2}{|c|}{$\begin{array}{c}\text { Incidence of DM } \\
\text { in year } 2 \\
(n=157)\end{array}$} & \multicolumn{2}{|c|}{$\begin{array}{c}\text { Incidence of } \\
\text { DM in year } 4 \\
(n=129)\end{array}$} & \multicolumn{2}{|c|}{$\begin{array}{c}\text { Incidence of } \\
\text { DM in year } 6 \\
(n=281)\end{array}$} \\
\hline & & $\mathbf{n}$ & $\%$ & $\mathbf{n}$ & $\%$ & $\mathbf{n}$ & $\%$ \\
\hline \multirow[t]{4}{*}{ Obesity } & None & 26 & 1.7 & 23 & 1.6 & 59 & 4.6 \\
\hline & Before diagnosis & 128 & 6.1 & 106 & 4.7 & 221 & 9.1 \\
\hline & At time of diagnosis & 2 & 6.1 & 0 & 0 & 1 & 4.8 \\
\hline & After diagnosis & 1 & 2.7 & 0 & 0 & - & - \\
\hline \multirow[t]{4}{*}{ Central obesity } & None & 13 & 1 & 15 & 1.4 & 39 & 4 \\
\hline & Before diagnosis & 141 & 6 & 112 & 4.3 & 240 & 8.8 \\
\hline & At time of diagnosis & 2 & 3.7 & 2 & 5.7 & 2 & 7.7 \\
\hline & After diagnosis & 60 & 1 & 0 & 0 & - & - \\
\hline \multirow[t]{4}{*}{ Hypertension } & None & 37 & 1.9 & 34 & 2 & 60 & 4.3 \\
\hline & Before diagnosis & 113 & 7 & 93 & 4.8 & 211 & 9.2 \\
\hline & At time of diagnosis & 4 & 5.5 & 1 & 2.7 & 10 & 20.8 \\
\hline & After diagnosis & 3 & 3.5 & 1 & 2.1 & - & - \\
\hline \multirow{4}{*}{ Increased total cholesterol } & None & 16 & 1.5 & 19 & 1.8 & 48 & 4.6 \\
\hline & Before diagnosis & 107 & 5.8 & 90 & 4.2 & 209 & 8.7 \\
\hline & At time of diagnosis & 16 & 5.3 & 13 & 5.6 & 24 & 8.1 \\
\hline & After diagnosis & 18 & 3.4 & 7 & 2.4 & - & - \\
\hline \multirow[t]{4}{*}{ Increased triglycerides } & None & 60 & 2.5 & 54 & 2.2 & 120 & 5 \\
\hline & Before diagnosis & 58 & 9.4 & 46 & 5.2 & 131 & 12.1 \\
\hline & At time of diagnosis & 29 & 10.6 & 14 & 7.1 & 30 & 12.4 \\
\hline & After diagnosis & 10 & 2.3 & 15 & 6.2 & - & - \\
\hline \multirow[t]{4}{*}{ Increased LDL } & None & 6 & 2.2 & 5 & 1.9 & 12 & 4.5 \\
\hline & Before diagnosis & 145 & 4.7 & 117 & 3.6 & 262 & 7.8 \\
\hline & At time of diagnosis & 5 & 2.5 & 5 & 5.1 & 7 & 7.5 \\
\hline & After diagnosis & 1 & 0.5 & 2 & 2.2 & - & - \\
\hline \multirow[t]{4}{*}{ Low HDL } & None & 44 & 2.9 & 38 & 2.5 & 94 & 6.2 \\
\hline & Before diagnosis & 81 & 5.5 & 73 & 4 & 172 & 8.7 \\
\hline & At time of diagnosis & 23 & 6.1 & 6 & 4.5 & 15 & 6.2 \\
\hline & After diagnosis & 9 & 2.4 & 12 & 5 & - & - \\
\hline \multirow[t]{4}{*}{$\mathrm{CHD}$} & None & 147 & 4.1 & 119 & 3.3 & 262 & 7.4 \\
\hline & Before diagnosis & 0 & 0 & 6 & 7.3 & 10 & 8.1 \\
\hline & At time of diagnosis & 5 & 6.1 & 3 & 7.1 & 9 & 19.1 \\
\hline & After diagnosis & 5 & 5.6 & 1 & 2.1 & - & - \\
\hline \multirow[t]{4}{*}{ Stroke } & None & 138 & 3.8 & 114 & 3.2 & 274 & 7.6 \\
\hline & Before diagnosis & 8 & 15.4 & 10 & 12.5 & 4 & 4 \\
\hline & At time of diagnosis & 5 & 17.9 & 1 & 5.3 & 3 & 8.8 \\
\hline & After diagnosis & 6 & 11.3 & 4 & 11.8 & - & - \\
\hline
\end{tabular}

Table 3. Determinants of combined incidence of DM and main comorbidity

\begin{tabular}{|c|c|c|c|c|}
\hline \multirow{2}{*}{ DM-comorbidity } & \multirow{2}{*}{ Determinant } & \multicolumn{2}{|c|}{ Adjusted* } & \multirow{2}{*}{ p value } \\
\hline & & HR & $95 \% \mathrm{CI}$ & \\
\hline \multirow{3}{*}{ DM-Increased LDL } & Obesity & 2.37 & $1.95-2.87$ & $<0.001$ \\
\hline & Hypertension & 1.51 & $1.25-1.83$ & $<0.001$ \\
\hline & Family history of DM & 1.47 & $1.17-1.84$ & $<0,001$ \\
\hline \multirow[t]{4}{*}{ DM-Central obesity } & Increased triglycerides & 2.32 & $1.89-2.84$ & $<0.001$ \\
\hline & Male gender & 2.23 & $1.74-2.85$ & $<0.001$ \\
\hline & Hypertension & 1.77 & $1.45-2.16$ & $<0.001$ \\
\hline & Family history of DM & 1.65 & $1.31-2.08$ & $<0.001$ \\
\hline \multirow[t]{2}{*}{ DM-Hypertension } & Obesity & 3.19 & $2.46-4.15$ & $<0.001$ \\
\hline & Increased triglycerides & 1.78 & $1.39-2.27$ & $<0.001$ \\
\hline
\end{tabular}

*controlled for age at baseline 
Obesity increased the risk of occurrence of the combined DM incidence-hypertension and DM incidence-increased LDL, with HR values of 3.19 (95\% CI: $2.45-4.15)$ and 2.37 (95\% CI: 1.95-2.87), respectively, in comparison with the non-obesiity groups. Males had a risk of 2.23 $(\mathrm{HR}=2.23 ; 95 \% \mathrm{CI}: 1.74-2.85)$ for the combined DM incidence-central obesity when compared with females. For the lipid profiles, although increased triglycerides were not the main comorbidity in the incidence of DM, they posed an important risk for the occurrence of the combined DM incidence-central obesity as well as that of DM incidence-hypertension.

\section{DISCUSSION}

Type $2 \mathrm{DM}$ is one of the principal NCDs in Indonesia. The presence of the comorbidity factor in patients with DM increases the risk of future complications, interferes with diabetic control, and reduces the patient's quality of life..$^{(1,13,14)}$

In the present study, only less than $5 \%$ of subjects did not have comorbidities from the start of the study up to the 6-year follow-up, signifying that nearly all subjects had comorbidities. This proportion is higher than that of other studies. For example in Croatia, according to Lang and Markovic, in subjects with DM in the healthcare service, a total of $77.7 \%$ had comorbidities, with mean comorbidity of $1.6 \pm 1.28$. $^{(24)}$ In the Netherlands, a cohort study found that according to the Continuous Morbidity Registration data, there were almost $85 \%$ of patients with comorbidities at initial diagnosis of DM. Around one-fourth of subjects without comorbidities at initial diagnosis of DM will suffer from at least one comorbidity in one year of follow-up. ${ }^{(5)}$

Based on the type of comorbidities, it was found that increased LDL occurred in nearly all of the subjects. Obesity, central obesity and increased total cholesterol occurred in around $80 \%$ of subjects, whereas hypertension occurred in more than $70 \%$ of subjects. This finding associated with hypertension was similar to other study results, but for dyslipidemia and obesity the results were different. According to Ekoru et al., ${ }^{(9)}$ the proportion of hypertension was $71 \%$, but that of dyslipidemia was only $34 \%$ and that of obesity $27 \%$. In other studies, hypertension was generally the main comorbidity in patients with DM. In Korea, from the results of further analysis of patients' medical records at Keimyung University, Dongsan, it was also found that the most common comorbidity was hypertension at $34.9 \%$, followed by gastritis at $15.6 \%$ and senile cataract at $15.4 \%$. $^{(7)}$ Hypertension as the most frequent comorbidity was also found in the most recent studies, such as the study in England by Nowakowska et al., ${ }^{(6)}$ the study on women of reproductive age in the US by Britton, ${ }^{(8)}$ and the study in sub-Saharan Africa by Ekoru. ${ }^{(9)}$ The finding associated with the high proportion of dyslipidemia merits special attention, in view of the fact that dyslipidemia is the primary risk for CHD and may play a role before the appearance of the other main risk factors. In patients with DM, dyslipidemia results in a higher risk of coronary abnormalities. ${ }^{(20)}$

The finding of CHD as comorbidity of DM in the present study differs from the results of previous studies. Only $6.4-7.8 \%$ of subjects with DM incidence had CHD as comorbidity. In contrast, based on the results of a study in Italy, from further analysis of several healthcare databases it was found that CHD was one of the most frequent comorbidities of DM with a proportion of $21.7 \%$. $^{(4)}$ The results of the study in Croatia also state that the most frequent comorbidities as complications of DM were polyneuropathy, $\mathrm{CHD}$, retinopathy, nephropathy, non-healing wounds, and amputations. ${ }^{(24)}$

Based on the results of the multivariate analysis, the determinants of the combined DM incidence-increased LDL were obesity, hypertension, and family history of DM. The determinants of the combined DM incidencecentral obesity were increased triglycerides, hypertension, male gender, and family history of DM, whereas the determinants of the combined DM incidence-hypertension were obesity and increased triglycerides. Regarding the combined 
DM incidence-increased LDL as well as the combined DM incidence-hypertension, the findings agreed with those of previous other studies that found increased BMI as one of the determinants. However, for the determinants of the combined DM incidence-central obesitythe present study found that the group of males had the higher risks, which is contrary to the other studies. ${ }^{(9)}$

In the present study it was found that obesity increased the risk of combined DM incidencehypertension. Obesity as determinant of hypertension in patients with DM is in line with the guidelines on the care of the comorbidities of DM by the American Diabetes Association. (25) In persons with diabetes there is a tendency of increased BMI as compared with healthy persons. The results of the NHANES longitudinal study in the US state that in the 20 years of study, among subjects with undiagnosed DM there was an increase in BMI from $31.5 \mathrm{~kg} / \mathrm{m}^{2}$ to $34.3 \mathrm{~kg} / \mathrm{m}^{2}$, whereas in subjects with diagnosed DM there was an increase in BMI from $28.1 \mathrm{~kg} / \mathrm{m}^{2}$ to 32.6 $\mathrm{kg} / \mathrm{m}^{2}{ }^{(26)}$

The presence of comorbidities of DM impacts on the occurrence of complications, such as cardiovascular disease. The accumulation of metabolic and cardiovascular risk factors in patients with DM may aggravate the condition and impede the attainment of therapeutic targets, which increases the risk of cardiovascular morbidity and mortality. ${ }^{(6)}$ This is in line with the results of a systematic review conducted by Einarson et al., ${ }^{(27)}$ indicating that the proportion of patients with DM and CHD was higher in the obese than in the non-obese and that there was a positive correlation between increased BMI and increased prevalence of heart disease in individuals with DM. Patients with DM have dysfunction of the blood vessel walls that may be triggered by environmental factors, such as sedentary life style, metabolic factors (chronic hyperglycemia, obesity) that is associated with increased regulation of reactive oxygen specie (ROS), chronic inflammation, and hypercoagulation, leading to atherosclerosis and cardiovascular disease. ${ }^{(6)}$

Based on the findings of the present study, a more comprehensive treatment of DM is necessary in patients with DM, i.e. regular taking of medications and having an increasingly healthy life style so that the treatment reaches its targets and reduces the risk factors of comorbidity. To this end, the follow-up of patients with DM at the community level should be increased through the NCD integrated health post (posbindu PTM) and household visits in the Healthy Indonesia through Family Approach Program (Program Indonesia Sehat melalui Pendekatan Keluarga, PIS-PK).

One of the limitations of the present study is the use of community-level data, so that there may be differences in results with those of other studies that use data from healthcare facilities. Another limitation is the short follow-up period (only 6 years), and the dearth of data on other comorbidities, i.e. the complications of DM, the study of which is still in the planning stage. By knowing the extent of the problem of the comorbidities of DM and their determinants, it is hoped that public health interventions may be instituted to prevent the occurrence of these comorbidities of DM.

It is necessary to conduct further cohort studies to determine the influence of comorbidities and the risk factors of the complications of DM, with the involvement of a larger number of associated determinants and longer observation periods.

\section{CONCLUSIONS}

In the six years of follow-up, the incidence of DM was 567 (15.2\%) subjects. The most frequent comorbidities were increased LDL, central obesity, increased total cholesterol, obesity and hypertension. These findings again highlight the importance of implementing an integrated approach for managing all these conditions since they are responsible for a substantial proportion of the burden of DM. 


\section{CONFLICT OF INTEREST}

\author{
None declared
}

\section{ACKNOWLEDGMENTS}

We hereby extend our gratitude to the National Institute of Health Research and Development (Badan Penelitian and Pengembangan Kesehatan), of the Bogor Municipal Health Service (Dinas Kesehatan Kota Bogor), the teams of experts/consultants, investigators, data collectors, and all subjects of the NCDRF cohort study.

\section{CONTRIBUTORS}

DK was the main contributor who was responsible for the initial design and data analysis. ER and NK were supporting contributors in directing the data analysis and final manuscript. ES and FD were supporting contributors in putting of the substance of the manuscript and its revision. All authors have read and approved the final version.

\section{REFERENCES}

1. International Diabetes Federation. IDF Diabetes Atlas 9th edition. Brussels: International Diabetes Federation; 2019.

2. Kementerian Kesehatan. Riset kesehatan dasar Riskesdas 2013. Jakarta: Kementerian Kesehatan Republik Indonesia; 2013.

3. Badan Penelitian dan Pengembangan Kesehatan. Laporan hasil riset kesehatan dasar (Riskesdas) Indonesia tahun 2018. Jakarta: Badan Penelitian dan Pengembangan Kesehatan; 2018.

4. Valent F, Tillati S, Zanier L. Prevalence and comorbidities of known diabetes in northeastern Italy. J Diabetes Investig 2013;4:355-60. doi: 10.1111/jdi.12043.

5. Luijks H, Schermer T, Bor H, et al. Prevalence and incidence density rates of chronic comorbidity in type 2 diabetes patients: an exploratory cohort study. BMC Med 2012;10:128. doi: 10.1186/17417015-10-128

6. Nowakowska M, Zghebi SS, Ashcroft DM, et al. The comorbidity burden of type 2 diabetes mellitus: patterns, clusters and predictions from a large English primary care cohort. BMC Med 2019;17:145. doi: 10.1186/s12916-019-1373-y.

7. Kim HS, ShinAM, Kim MK, Kim YN. Comorbidity study on type 2 diabetes mellitus using data mining. Korean J Intern Med 2012;27:197-202. doi: 10.3904/kjim.2012.27.2.197.

8. Britton LE, Berry DC, Hussey JM. Comorbid hypertension and diabetes among US women of reproductive age: prevalence and disparities. J Diabetes Complicat2018;32:1148-52. doi: 10.1016/ j.jdiacomp.2018.09.014.

9. Ekoru K, Doumatey A, Bentley AR, et al. Type 2 diabetes complications and comorbidity in SubSaharan Africans. EClinicalMedicine 2019;16:30 41. doi: 10.1016/j.eclinm.2019.09.001.

10. PB PERKENI. Pedoman pengelolaan dan pencegahan diabetes melitus tipe 2 dewasa di Indonesia. Edisi Pertama. Jakarta: PB Perkeni; 2019

11. Fajarini IA, Sartika RAD. Obesitas sebagai komorbiditas diabetes tipe 2: perilaku makan dan determinan lain pada pasien diabetes tipe $2 \mathrm{di}$ Jakarta, Indonesia. National Public Health 2019;13: 157-63. doi: 10.21109/kesmas.v13i4.2483.

12. Lin PJ, Pope E, Zhou FL. Comorbidity type and health care costs in type 2 diabetes: a retrospective claims database analysis. Diabetes Ther 2018;9: 1907-18. doi: 10.1007/s13300-018-0477-2.

13. Larkin ME, Walders-Abramson N, Hirst K, et al. Effects of comorbid conditions on health-related quality of life in youth with type 2 diabetes: the TODAY clinical trial. Diabetes Manag 2015;5:4319. DOI: $10.2217 / \mathrm{dmt} .15 .35$.

14. Alonso-Morán E, Orueta JF, Esteban JIF, ert al. The prevalence of diabetes related complications and multimorbidity in the population with type 2 diabetes mellitus in the Basque Country. BMC Public Health 2014;14:1059. doi:10.1186/14712458-14-1059.

15. Pantalone KM, Hobbs TM, Wells BJ, et al. Clinical characteristics, complications, comorbidities and treatment patterns among patients with type 2 diabetes mellitus in a large integrated health system. BMJ Open Diabetes Res Care 2015;3:e000093. doi: 10.1136/bmjdrc-2015000093.

16. Jelinek HF, Osman WM, Khandoker AH et al. Clinical profiles, comorbidities and complications of type 2 diabetes mellitus in patients from United Arab Emirates. BMJ Open Diab Res Care 2017;5:e000427. doi: 10.1136/bmjdrc-2017-000427.

17. Wang B, Zhang M, Wang S, et al. Dynamic status of metabolically healthy overweight obesity and metabolically unhealthy and normal and the risk of type 2 diabetes mellitus: a cohort study of a 
rural Chinese adult population. Obes Res Clin Pract 2018;12:61-71. doi: 10.1016/j.orcp.2017. 10.005

18. Riyadina W, Sudikno, Rahajeng E, et al. Laporan studi kohor faktor risiko penyakit tidak menular 2018. Jakarta Pusat: Puslitbang Upaya Kesehatan Masyarakat; 2018.

19. Tim Penyusun Revisi Pedoman Pengelolaan Dislipidemia di Indonesia. Pedoman pengelolaan dislipidemia di Indonesia. Edisi Pertama. Jakarta: PB Perkeni; 2019.

20. Armstrong C. JNC-8 guidelines for the management of hypertension in adults. Am Fam Physician 2014;90:503-4.

21. Poggio R, Serón P, Calandrelli M, et al. Prevalence, patterns, and correlates of physical activity among the adult population in Latin America: cross-sectional results from the CESCAS I Study. Glob Heart 2016;11:81-8.e1. doi: 10.1016/j.gheart. 2015.12.013.

22. Netsereab TB, Kifle MM, Tesfagiorgis RB, Habteab SG, Weldeabzgi YK, Tesfamariam OZ. Validation of the WHO self-reporting questionnaire-20 (SRQ-20) item in primary health care settings in Eritrea. Int $\mathrm{J}$ Ment Health Syst 2018;12:61. doi: 10.1186/s13033-018-0242-y.

23. World Health Organization. STEPwise approach to noncommunicable disease risk factor surveillance (STEPS). Geneva: World Health Organization; 2017.
24. Lang VB, Marković BB. Prevalence of comorbidity in primary care patients with type 2 diabetes and its association with elevated HbAlc: a crosssectional study in Croatia. Scand J Prim Health Care 2016;34:66-72. doi: 10.3109/02813432.2015. 1132886.

25. American Diabetes Association. 2. Classification and diagnosis of diabetes: standards of medical care in diabetes-2020. Diabetes Care 2020;43(Suppl 1): S14-31. doi: 10.2337/dc20-S002

26. Kramer H, Cao G, Dugas L, Luke A, Cooper R, Durazo-Arvizu R. Increasing BMI and waist circumference and prevalence of obesity among adults with Type 2 diabetes: the National Health and Nutrition Examination Surveys. J Diabetes Complications 2010;24:368-74. doi: 10.1016/ j.jdiacomp.2009.10.001.

27. Einarson TR, Acs A, Ludwig C, Panton UH. Prevalence of cardiovascular disease in type 2 diabetes: a systematic literature review of scientific evidence from across the world in 20072017. Cardiovasc Diabetol 2018;17:83. doi: 10.1186/s12933-018-0728-6 